\title{
Cancer risk factors and screening in First Nations in Ontario
}

\section{Maegan V. Mazereeuw, MPH (1); Alexander Yurkiewich, MSc (2); Sehar Jamal, MPH (1); Caroline Cawley, MPH (1); Carmen R. Jones, BA (2); Loraine D. Marrett, PhD (1,3)}

This article has been peer reviewed.

Tweet this article

\begin{abstract}
Introduction: A lack of identifiers in health administrative databases limits our understanding of the cancer burden in First Nations. This study compares cancer risk factors and screening between First Nations in Ontario (on and off reserve) and non-Aboriginal Ontarians using two unique health surveys.
\end{abstract}

Methods: We measured age-standardized prevalence estimates using the First Nations Regional Health Survey (RHS) Phase 2, 2008/10 (for First Nations on reserve) and the Canadian Community Health Survey (CCHS), 2007-2013 (for First Nations off reserve and non-Aboriginal Ontarians). We used prevalence rate ratios (RR) and Pearson's chisquare tests for differences in proportions to compare estimates between First Nations (on and off reserve) and non-Aboriginal Ontarians.

Results: A higher proportion of First Nation men, women and adolescents on reserve smoked $(\mathrm{RR}=1.97,2.78$ and 7.21 respectively) and were obese $(\mathrm{RR}=1.73,2.33$ and 3.29 respectively) compared to their non-Aboriginal counterparts. Similar patterns were observed for First Nations off reserve. Frequent binge drinking was also more prevalent among First Nation men and women living on reserve $(R R=1.28$ and 2.22, respectively) and off reserve ( $\mathrm{RR}=1.70$ and 1.45 , respectively) than non-Aboriginal Ontarians. First Nation men and women on reserve were about half as likely to consume fruit at least twice per day and vegetables at least twice per day compared to non-Aboriginal men and women ( $R R=0.53$ and 0.54 , respectively). Pap test uptake was similar across all groups, while First Nation women on reserve were less likely to have had a mammogram in the last five years than non-Aboriginal women $(R R=0.85)$.

Conclusion: First Nations, especially those living on reserve, have an increased risk for cancer and other chronic diseases compared to non-Aboriginal Ontarians. These results provide evidence to support policies and programs to reduce the future burden of cancer and other chronic diseases in First Nations in Ontario.

Keywords: First Nations, cancer risk factors, cancer screening

\section{Introduction}

First Nations are the largest of three groups collectively recognized by Canada's Constitution Act of 1982 as the "Aboriginal peoples of Canada." There are more First Nation people living in Ontario than in any other province or territory in Canada. ${ }^{2}$ About half of all First Nations in Ontario live on reserves (46\%), which are tracts of land set aside by the Canadian government for the use of First Nation communities. ${ }^{3}$
First Nations have experienced a long history of colonization and loss of cultural identity, which has dramatically impacted their way of life and all aspects of their health. The impact of these actions on health and well-being continues today. Across Canada, First Nations experience significantly lower rates of high school graduation, lower median personal income and more than twice the rate of unemployment compared to non-Aboriginal Canadians. ${ }^{4}$ These inequities have contributed

\section{Highlights}

- First Nation adults living on and off reserve are two to three times more likely to smoke cigarettes than non-Aboriginal adults.

- Among First Nations living on reserve, the prevalence of obesity was three times higher, and the proportion who ate fruit at least twice per day and vegetables at least twice per day was about half of that for non-Aboriginal Ontarians.

- First Nation women living on reserve are less likely to have had a mammogram for breast cancer in the last five years compared to non-Aboriginal women

- These results demonstrate that actions to improve the health of First Nations in Ontario (whether on or off reserve) are needed to reduce their future burden of cancer and other chronic diseases.

to major health consequences in the First Nation population, including significantly lower life expectancy ${ }^{5}$ and a higher prevalence of chronic conditions. ${ }^{6}$

A lack of ethnic identifiers in Canadian health databases, including the Ontario Cancer Registry, has resulted in a gap in information about the burden of chronic diseases, such as cancer, in First Nations. In one study, the Ontario portion of the Indian Registry System (IRS) was linked with the Ontario Cancer Registry (19681991). ${ }^{7}$ The study found cancer incidence was increasing disproportionately among First Nations compared to non-First Nations. A follow-up to this study found cancer survival was poorer for First

\section{Author references:}

1. Aboriginal Cancer Control Unit, Cancer Care Ontario, Toronto, Ontario, Canada

2. Health Sector, Chiefs of Ontario, Toronto, Ontario, Canada

3. Dalla Lana School of Public Health, University of Toronto, Toronto, Ontario, Canada

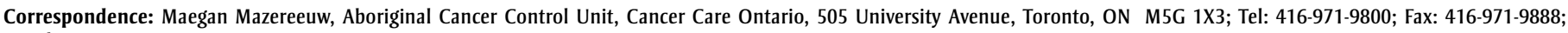
Email: maegan.mazereeuw@cancercare.on.ca 
Nations than non-First Nations in Ontario for various cancer sites. ${ }^{8}$

In the absence of more recent First Nations-specific cancer data, studying the prevalence of cancer risk factors and screening using population health surveys offers a timely approach to determining how and where prevention resources can be most effectively directed to reduce the future burden of cancer. Evidence confirms strong associations between five major risk factors related to lifestyle (tobacco smoking, alcohol consumption, body composition, physical inactivity and diet) and the risk of certain cancers. ${ }^{9,10}$ Many of these factors are also common to other chronic diseases, such as cardiovascular disease, diabetes and respiratory diseases. ${ }^{11}$ Thus, prevention efforts to address lifestyle risk factors will not only impact the future burden of cancer but also the burden of many other common and costly chronic conditions. One other study found many lifestyle risk factors for cancer to be more prevalent among the off-reserve First Nation population compared to nonAboriginal Ontarians. ${ }^{12}$ No study has examined cancer risk and screening in First Nations living on reserve in Ontario. This study aims to compare risk factors for cancer and screening participation as accurately as possible between First Nations in Ontario (both on and off reserve) and the non-Aboriginal population using two health surveys.

\section{Methods}

\section{Data sources}

Data for First Nations living off reserve in Ontario and non-Aboriginal Ontarians were obtained from the Ontario portion of the Canadian Community Health Survey (CCHS) cycles 2007-2013 (seven cycles for most questions; three cycles for cancer screening questions). Between 2007 and 2013, the CCHS response rate in Ontario varied from $65.8 \%$ to $73.6 \% .{ }^{13-19}$ The CCHS, administered by Statistics Canada, is a population-based survey of the Canadian population aged 12 years and over living in all provinces and territories, excluding individuals living on Indian reserves and Crown lands, institutional residents, full-time members of the Canadian Forces and residents of some remote regions. ${ }^{20}$ To increase the sample size of First Nations living off reserve available for analysis, microdata files for seven annual releases of the CCHS
(2007-2013) were combined as per methodology described by Statistics Canada. ${ }^{21}$ Data for First Nations living on reserve were obtained from the Ontario portion of the First Nations Regional Health Survey (RHS) Phase 2 (2008/10), governed by the First Nations Information Governance Centre. The RHS is the only First Nationsgoverned national health survey that collects information about First Nations living on reserve and in northern First Nation communities aged 12 years and over. $^{22}$ The RHS Phase 2 was initiated in the spring of 2008 and completed in the fall of 2010. It was a single survey, with the data collection phase occurring over an 18-month period. Of 133 First Nation communities in Ontario, a total of 24 participated in the RHS Phase $2(2008 / 10)$. The target sample for the RHS Ontario region was 4551 First Nation individuals, of which 2870 completed questionnaires $(63.1 \%){ }^{23}$

\section{Indicators of risk and screening}

Unless otherwise specified, risk factor analyses included adult respondents aged 18 years and older, and adolescent respondents aged 12 to 17 years. We excluded respondents with a missing or invalid response to a given question from the denominator of that indicator. We based age limits and response cut-off points for each screening measure on Ontario guidelines for that screening modality. For cancer screening, relevant questions were only posed in the 2007, 2008 and 2011 CCHS surveys.

Our definition of each indicator is provided below:

Smoking: The proportion of respondents aged 20 years and older who reported smoking daily or occasionally. A cut-off of age 20 years was chosen to be consistent with other public health indicators. ${ }^{24}$ The CCHS and RHS had equivalent questions and response categories for measurement of smoking.

Obesity: The proportion of respondents who, based on self-reported height and weight, had a body mass index (BMI) of $30 \mathrm{~kg} / \mathrm{m}^{2}$ or more. Pregnant and lactating women were excluded. The CCHS and RHS had equivalent questions and response categories for measurement of obesity.
Physical activity: The proportion of respondents classified as moderately active in the previous three months, based on daily estimated energy expenditure (EE) exceeding $1.5 \mathrm{kcal} / \mathrm{kg} /$ day. To determine $\mathrm{EE}$, respondents were asked about the frequency and duration of different activities. The CCHS asks respondents about physical activity during leisure activities, while the RHS does not specify during leisure activities (therefore, the RHS indicator may also include, for example, physical activity for transportation or occupation). There was also some variation in types of activities between surveys. For example, in the RHS, traditional activities were included (such as hunting or trapping, fishing and berry picking or other food gathering). These were not listed as activities in the CCHS. In the CCHS and RHS, EE was calculated by combining information on frequency and duration with the metabolic equivalent of the activity, which takes into account the intensity of the activity.

Vegetable and fruit consumption: The proportion of respondents who ate vegetables (including potatoes) at least two times per day and fruit at least two times per day. This indicator is typically measured as consuming vegetables and fruit five or more times per day (in any combination, and excluding potatoes) as per the cancer prevention guidelines; 9 however, in the RHS, there are only two response categories to choose from when asked about average daily consumption of vegetables (which could include potatoes) or fruit: "once a day" or "several times a day." Respondents to the RHS who selected "several times a day" for both vegetables and fruit were included in our definition as having consumed fruit at least twice and vegetables at least twice, for a combined total of four or more times per day. For consistency, respondents to the CCHS who reported eating at least two vegetables (including potatoes) and at least two fruits were included in our definition as consuming fruit and vegetables a combined total of four or more times per day.

Alcohol abstinence: The proportion of respondents aged 19 years and older who reported not having an alcoholic drink in the previous 12 months. Pregnant women were excluded. The RHS and CCHS had equivalent questions and response categories for measurement of alcohol abstinence. 
Frequent binge drinking: The proportion of respondents aged 19 years and older who reported having five or more drinks on one occasion at least two to three times per month in the previous 12 months. Pregnant women were excluded. The RHS and CCHS had equivalent questions and response categories for measurement of binge drinking.

Frequent binge drinking and smoking: The proportion of respondents aged 19 years and older who reported having five or more drinks on one occasion at least two to three times per month in the previous 12 months and who were current smokers. Pregnant women were excluded. The RHS and CCHS had equivalent questions and response categories for measurement of binge drinking and current smoking.

Cervical screening participation: The proportion of women aged 21 to 69 years who had a Pap test within the previous three years. There is no question in the RHS that asks women if they have had a total hysterectomy; therefore, women who indicated that they had a hysterectomy in the CCHS were included.

Breast screening participation: The proportion of women aged 50 to 74 years who had a mammogram within the previous five years. This indicator deviates from the recommended interval of breast cancer screening (every two years for women at average risk) to enable comparison between response categories of the RHS and CCHS (the RHS only asks women if they had a mammogram in the past one to three years or three to five years). Additionally, there is no question in the RHS that asks why a woman had a mammogram (e.g. for follow-up treatment, diagnosis or other breast problems); therefore, respondents to the CCHS who indicated they had a mammogram for reasons other than screening were also included in the definition.

\section{Aboriginal identity}

From 2007 to 2010, all CCHS respondents were asked "Are you an Aboriginal person, that is, North American Indian, Métis or Inuit?" Respondents who answered "yes" were also asked to specify the subpopulation to which they belonged, and a respondent could report multiple Aboriginal identities. As of 2011, the CCHS question about Aboriginal identity was restricted to those born in Canada, the United States, Germany or Greenland. To be consistent, we classified respondents in 2007 to 2010 as First Nations only if they had also reported being born in one of these four countries. "First Nations living off reserve" included those who responded to the CCHS and self-identified as First Nations or First Nations and Inuit. "Non-Aboriginal Ontarians" were defined as respondents to the CCHS who did not self-identify as Aboriginal, or who self-identified as Aboriginal but were born outside of Canada, the United States, Germany and Greenland. "First Nations living on reserve" were all those who responded to the RHS.

\section{Age groups, education and geography}

In our risk factor analyses, we stratified adults by age according to the following standard groupings: youngest age for indicator $(18,19$ or 20$)$ to 29 years; 30 to 44 years; 45 to 64 years; and 65 years or older. For cervical cancer screening, we defined age groups as 21 to 29 years; 30 to 44 years; and 45 to 69 years. For breast cancer screening, we defined age groups as 50 to 54 years; 55 to 64 years; and 65 to 74 years.

We categorized respondents' level of education into three groups based on the highest level of schooling attained: less than secondary school graduation, secondary school graduation and/or some postsecondary and post-secondary graduation.

We categorized geography of residence into north or south based on Statistics Canada's census divisions. We classified south as census division codes 3501 through 3547, and north as census division codes 3548 through 3560 . According to this definition, of the 24 First Nation communities that participated in the RHS, 10 were located in the south of the province and 14 were located in the north. For instance, Moose Deer Point First Nation would be classified as south, and Wasauksing First Nation would be classified as north. A map showing the geography of north and south according to this definition, as well as First Nation communities that participated in the RHS, has been published. ${ }^{25}$

\section{Analysis}

Sampling weights assigned by Statistics Canada (for the CCHS) or the First Nations Information Governance Centre (for the
RHS) were used to account for selection probability, nonresponse and noncoverage. We measured age-standardized prevalence (ASP) according to the 2006 Ontario Aboriginal identity population ${ }^{26}$ and stratified it by gender, age group, education and geography. We used bootstrapping techniques to calculate the coefficient of variation (CV) and $95 \%$ confidence intervals (CIs). Estimates with a $\mathrm{CV}$ ranging from $16 \%$ to $33 \%$ were flagged to be interpreted with caution. We performed prevalence rate ratios and chisquare tests to compare estimates between First Nations and non-Aboriginal Ontarians. A $p$-value $<.05$ was considered statistically significant.

\section{Results}

The RHS identified 1500 First Nation adults and 600 First Nation adolescents living on reserve; the CCHS identified 2119 First Nation adults and 376 adolescents, and 123105 non-Aboriginal adults and 11636 adolescents living off reserve (Table 1).

First Nation adults living on reserve (ASP men $=50.4 \%$, ASP women $=49.4 \%$ ) and off reserve (ASP men $=44.2 \%$, ASP women $=41.4 \%$ ) had a significantly higher prevalence of smoking compared with non-Aboriginal adults (ASP men $=25.6 \%$, ASP women $=17.8 \%$ ) (Table 2, Figures 1 and 2). First Nation adolescents living on reserve (ASP $=30.3 \%)$ and off reserve (ASP $=13.8 \%$ ) were also significantly more likely to smoke compared to non-Aboriginal adolescents $(\mathrm{ASP}=4.2 \%)$.

A significantly higher proportion of First Nation adults living on reserve (ASP men $=34.8 \%$, ASP women $=37.8 \%)$ and men living off reserve (ASP $=18.9 \%$ ) reported abstaining from alcohol compared with their non-Aboriginal counterparts (ASP men $=15.7 \%$, ASP women $=24.5 \%)$. First Nation women living off reserve had a similar prevalence of alcohol abstinence compared to nonAboriginal women (24.2\% vs. $24.5 \%$ ).

First Nation men and women living off reserve (ASP men $=27.7 \%$, ASP women $=10.7 \%)$ were significantly more likely to binge drink frequently compared to non-Aboriginal men and women (ASP men $=19.1 \%$, ASP women $=6.3 \%)$. Among First Nations living on reserve, a similar proportion of men (ASP $=24.5 \%$ ) and a significantly higher proportion of 
TABLE 1

Sample sizes available for First Nations living on reserve (RHS, 2008/10), First Nations living off reserve and non-Aboriginal population (CCHS, 2007-2013), Ontario, Canada

\begin{tabular}{lccc}
\multicolumn{1}{c}{ Age group } & $\begin{array}{c}\text { Non-Aboriginal } \\
\text { population (CCHS) }\end{array}$ & $\begin{array}{c}\text { Off-reserve First } \\
\text { Nations (CCHS) }\end{array}$ & $\begin{array}{c}\text { On-reserve First Nations } \\
\text { (RHS) }\end{array}$ \\
\hline Adolescents (12-17) & 11636 & 376 & 600 \\
Men (18+) & 54742 & 919 & 654 \\
Women (18+) & 68363 & 1200 & 846 \\
Women (21-69) & 26183 & 619 & 719 \\
Women (50-74) $^{\mathrm{b}}$ & 29366 & 442 & 362 \\
\hline
\end{tabular}

Abbreviations: CCHS, Canadian Community Health Survey; RHS, First Nations Regional Health Survey.

${ }^{a}$ Eligible for cervical cancer screening (Pap test) indicator.

${ }^{\mathrm{b}}$ Eligible for breast cancer screening (mammogram) indicator. women $(\mathrm{ASP}=14.0 \%)$ reported frequent binge drinking compared to non-Aboriginal men and women. The prevalence of combined frequent binge drinking and smoking was significantly higher among First Nation men and women living on reserve (ASP men $=15.6 \%$, ASP women $=10.4 \%$ ) and off reserve (ASP men $=17.7 \%$, ASP women $=7.5 \%$ ) compared to non-Aboriginal men and women (ASP men $=8.0 \%$, ASP women $=2.7 \%)$.

First Nations living on reserve (ASP men $=12.0 \%$, ASP women $=19.9 \%)$ and women living off reserve (ASP $=27.7 \%$ ) were significantly less likely to report eating vegetables at least twice and fruit at

TABLE 2

Age-standardized prevalence (\%) of risk factors for cancer and cancer screening in First Nations (on and off reserve) and non-Aboriginal people, Ontario, Canada (CCHS, 2007-2013 and RHS, 2008/10)

\begin{tabular}{|c|c|c|c|c|c|c|c|c|c|}
\hline \multirow[t]{2}{*}{ Characteristic } & \multirow[t]{2}{*}{$\begin{array}{c}\text { Subgroup } \\
\text { (age in years) }\end{array}$} & \multicolumn{2}{|c|}{$\begin{array}{l}\text { Non-Aboriginal } \\
\text { population } \\
\text { (CCHS) }\end{array}$} & \multicolumn{3}{|c|}{$\begin{array}{l}\text { Off-reserve First Nations } \\
\text { (CCHS) }\end{array}$} & \multicolumn{3}{|c|}{$\begin{array}{l}\text { On-reserve First Nations } \\
\text { (RHS) }\end{array}$} \\
\hline & & $\%$ & Cl & $\%$ & $\mathbf{C l}$ & $\begin{array}{l}\text { Prevalence } \\
\text { rate ratio }\end{array}$ & $\%$ & Cl & $\begin{array}{c}\text { Prevalence } \\
\text { rate ratio }\end{array}$ \\
\hline \multicolumn{10}{|c|}{ Risk/protective factors } \\
\hline Smoking & $\begin{array}{l}\text { Adolescents (12-17) } \\
\text { Men }(20+) \\
\text { Women }(20+)\end{array}$ & $\begin{array}{r}4.2 \\
25.6 \\
17.8\end{array}$ & $\begin{array}{c}3.8-4.7 \\
24.9-26.4 \\
17.2-18.3\end{array}$ & $\begin{array}{l}13.8 \\
44.2 \\
41.4\end{array}$ & $\begin{array}{r}9.0-18.6 \\
39.1-49.2 \\
36.4-46.4\end{array}$ & $\begin{array}{l}3.29 \\
1.73 \\
2.33\end{array}$ & $\begin{array}{l}30.3 \\
50.4 \\
49.4\end{array}$ & $\begin{array}{l}24.8-36.4 \\
45.4-55.4 \\
45.3-53.5\end{array}$ & $\begin{array}{l}7.21 \\
1.97 \\
2.78\end{array}$ \\
\hline $\begin{array}{l}\text { Abstaining from } \\
\text { alcohol }\end{array}$ & $\begin{array}{l}\text { Men }(19+) \\
\text { Women }(19+)\end{array}$ & $\begin{array}{l}15.7 \\
24.5\end{array}$ & $\begin{array}{l}15.1-16.4 \\
23.7-25.3\end{array}$ & $\begin{array}{l}18.9 \\
24.2\end{array}$ & $\begin{array}{l}14.3-23.5 \\
20.2-28.3\end{array}$ & $\begin{array}{l}1.20 \\
0.99^{\mathrm{NS}}\end{array}$ & $\begin{array}{l}34.8 \\
37.8\end{array}$ & $\begin{array}{l}30.1-39.5 \\
33.8-41.9\end{array}$ & $\begin{array}{l}2.22 \\
1.54\end{array}$ \\
\hline $\begin{array}{l}\text { Frequent binge } \\
\text { drinking }\end{array}$ & $\begin{array}{l}\text { Men }(19+) \\
\text { Women }(19+)\end{array}$ & $\begin{array}{r}19.1 \\
6.3\end{array}$ & $\begin{array}{c}18.5-19.7 \\
5.9-6.6\end{array}$ & $\begin{array}{l}27.7 \\
10.7\end{array}$ & $\begin{array}{r}22.9-32.4 \\
7.8-13.6\end{array}$ & $\begin{array}{l}1.45 \\
1.70\end{array}$ & $\begin{array}{l}24.5 \\
14.0\end{array}$ & $\begin{array}{r}20.4-28.6 \\
11.1-16.8\end{array}$ & $\begin{array}{l}1.28 \\
2.22\end{array}$ \\
\hline $\begin{array}{l}\text { Smoking and } \\
\text { frequent binge } \\
\text { drinking }\end{array}$ & $\begin{array}{l}\text { Men }(19+) \\
\text { Women }(19+)\end{array}$ & $\begin{array}{l}8.0 \\
2.7\end{array}$ & $\begin{array}{l}7.6-8.4 \\
2.4-2.9\end{array}$ & $\begin{array}{r}17.7 \\
7.5\end{array}$ & $\begin{array}{r}13.5-22.0 \\
4.9-10.1\end{array}$ & $\begin{array}{l}2.21 \\
2.78\end{array}$ & $\begin{array}{l}15.6 \\
10.4\end{array}$ & $\begin{array}{r}12.1-19.0 \\
8.0-12.9\end{array}$ & $\begin{array}{l}1.95 \\
3.85\end{array}$ \\
\hline $\begin{array}{l}\text { Eating fruit at least } \\
\text { twice and } \\
\text { vegetables at least } \\
\text { twice per day }\end{array}$ & $\begin{array}{l}\text { Men }(18+) \\
\text { Women }(18+)\end{array}$ & $\begin{array}{l}22.8 \\
37.0\end{array}$ & $\begin{array}{l}22.2-23.4 \\
36.3-37.7\end{array}$ & $\begin{array}{l}21.9 \\
27.7\end{array}$ & $\begin{array}{l}17.7-26.1 \\
23.2-32.2\end{array}$ & $\begin{array}{l}0.96^{\mathrm{NS}} \\
0.75\end{array}$ & $\begin{array}{l}12.0 \\
19.9\end{array}$ & $\begin{array}{r}9.2-14.8 \\
16.8-23.0\end{array}$ & $\begin{array}{l}0.53 \\
0.54\end{array}$ \\
\hline Obese & $\begin{array}{l}\text { Adolescents (12-17) } \\
\text { Men (18+) } \\
\text { Women }(18+)\end{array}$ & $\begin{array}{r}4.8 \\
18.7 \\
16.2\end{array}$ & $\begin{array}{c}4.2-5.4 \\
18.1-19.3 \\
15.8-16.7\end{array}$ & $\begin{array}{r}7.5^{\mathrm{a}} \\
33.0 \\
27.9\end{array}$ & $\begin{array}{r}3.9-11.0 \\
27.9-38.1 \\
23.6-32.3\end{array}$ & $\begin{array}{l}1.56 \\
1.76 \\
1.72\end{array}$ & $\begin{array}{l}15.9 \\
48.1 \\
49.4\end{array}$ & $\begin{array}{r}13.3-18.9 \\
43.2-53.0 \\
45.3-53.5\end{array}$ & $\begin{array}{l}3.31 \\
2.57 \\
3.05\end{array}$ \\
\hline Physically active & $\begin{array}{l}\text { Men }(18+) \\
\text { Women }(18+)\end{array}$ & $\begin{array}{l}53.4 \\
47.9\end{array}$ & $\begin{array}{l}52.5-54.2 \\
47.1-48.6\end{array}$ & $\begin{array}{l}59.8 \\
49.7\end{array}$ & $\begin{array}{l}54.4-65.2 \\
45.2-54.2\end{array}$ & $\begin{array}{l}1.12 \\
1.04^{\mathrm{NS}}\end{array}$ & $\begin{array}{l}43.9 \\
26.5\end{array}$ & $\begin{array}{l}39.1-48.6 \\
23.0-30.1\end{array}$ & $\begin{array}{l}0.82 \\
0.55\end{array}$ \\
\hline Cancer screening & & & & & & & & & \\
\hline $\begin{array}{l}\text { Pap test in the last } \\
3 \text { years }\end{array}$ & Women (21-69) & 77.7 & 76.9-78.6 & 77.4 & $72.9-81.9$ & $1.00^{\mathrm{NS}}$ & 76.9 & $73.3-80.5$ & $0.99^{\mathrm{NS}}$ \\
\hline $\begin{array}{l}\text { Mammogram in } \\
\text { the last } 5 \text { years }\end{array}$ & Women (50-74) & 82.1 & $80.6-83.6$ & 81.7 & $73.7-89.8$ & $1.00^{\mathrm{NS}}$ & 69.8 & $63.8-75.7$ & 0.85 \\
\hline
\end{tabular}

Abbreviations: CCHS, Canadian Community Health Survey; Cl, confidence interval; NS, not significant ( $p>.05)$; RHS, First Nations Regional Health Survey

a High sampling variability; interpret with caution. 
FIGURE 1

Age-standardized prevalence (\%) of risk and protective factors for cancer in First Nation and non-Aboriginal adult males, Ontario, Canada

\section{Males}

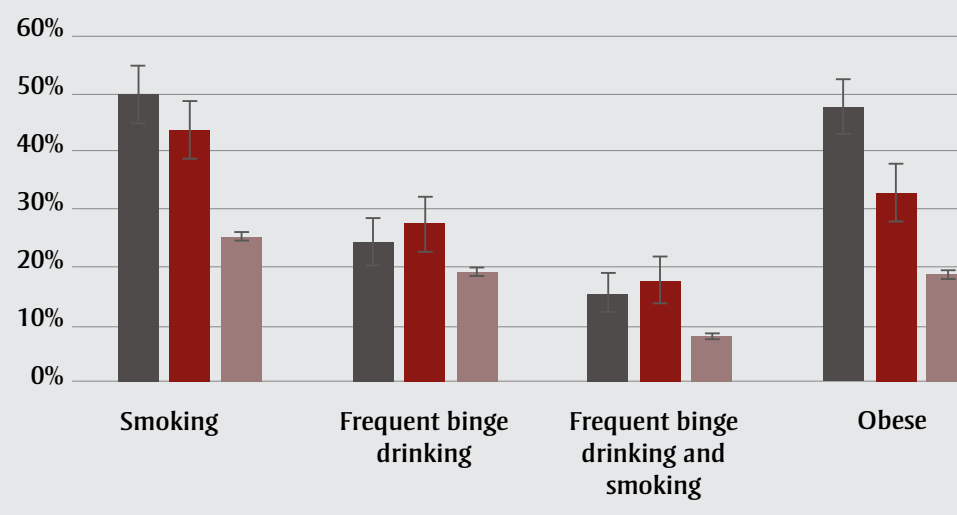

Risk factors

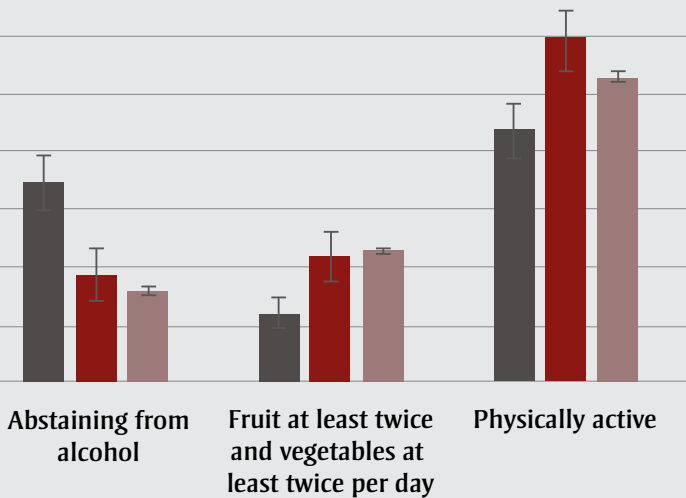

Protective factors

Data source: First Nations Regional Health Survey (RHS) 2008/10; Canadian Community Health Survey (CCHS) 2007-2013.

Notes: Age-standardized to the 2006 Ontario Aboriginal identity population. For age ranges for each variable, see text or Table 2 . I represents $95 \%$ confidence interval.

FIGURE 2

Age-standardized prevalence (\%) of risk and protective factors for cancer and cancer screening in First Nation and non-Aboriginal adult females, Ontario, Canada

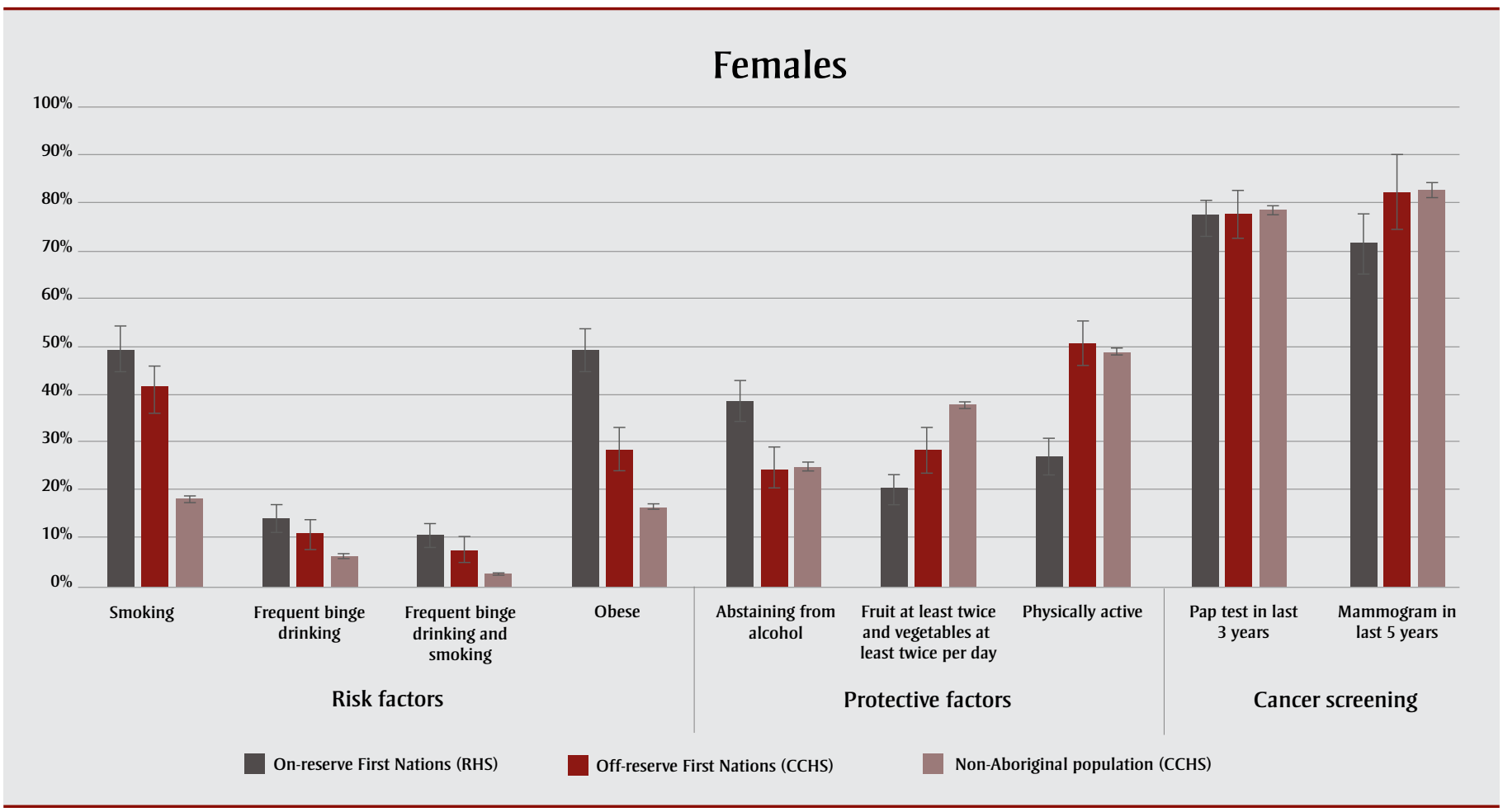

Data source: Canadian Community Health Survey (CCHS) 2007-2013 (7 cycles for most questions, 3 cycles for cancer screening); First Nations Regional Health Survey (RHS) 2008/10.

Notes: Age-standardized to the 2006 Ontario Aboriginal identity population. For age ranges for each variable, see text or Table 2 . I represents $95 \%$ confidence interval. 
least twice per day compared to nonAboriginal adults (ASP men $=22.8 \%$, ASP women $=37.0 \%$ ). The prevalence of obesity was significantly higher among First Nation adults living on reserve (ASP men $=48.1 \%$, ASP women $=49.4 \%$ ) and off reserve (ASP men $=33.0 \%$, ASP women $=27.9 \%$ ) compared to nonAboriginal adults (ASP men $=18.7 \%$, ASP women $=16.2 \%)$. Among First Nation adolescents, those living on reserve $(\mathrm{ASP}=15.9 \%)$ and off reserve $($ ASP $=7.5 \%)$ were more likely to be obese compared to non-Aboriginal adolescents $(\mathrm{ASP}=4.8 \%)$.

A significantly lower proportion of First Nation men and women living on reserve were physically active (ASP men $=43.9 \%$, ASP women $=26.5 \%$ ) compared to nonAboriginal men and women (ASP men $=53.4 \%$, ASP women $=47.9 \%)$. Among First Nations living off reserve, a significantly higher proportion of men $(\mathrm{ASP}=59.8 \%)$ and a similar proportion of women (ASP $=49.7 \%$ ) were physically active compared to non-Aboriginal men and women.

A similar proportion of First Nation women living on reserve (ASP $=76.9 \%$ ) and off reserve (ASP $=77.4$ ) were screened for cervical cancer in the last three years compared to non-Aboriginal women $($ ASP $=77.7 \%)$. However, the prevalence of mammogram uptake in the last five years was significantly lower among First Nation women living on reserve (ASP $=69.8 \%$ ) compared to nonAboriginal women $($ ASP $=82.1 \%$ ). First Nation women living off reserve were equally likely to have had a mammogram in the last five years (ASP $=81.7 \%$ ) as non-Aboriginal women $($ ASP $=82.1 \%)$.

The results for both on and off reserve First Nations compared to non-Aboriginal Ontarians generally remained consistent within age groups, levels of education and north/south geography, with wide confidence intervals indicating a large amount of variation in the estimates (data not shown).

\section{Discussion}

Across several indicators of lifestyle-associated risk presented in this study, First Nations in Ontario (especially those living on reserve) fared worse than non-Aboriginal Ontarians, suggesting they may experience a greater future burden of cancer and other chronic diseases. The high prevalence of smoking and obesity, low prevalence of fruit and vegetable consumption and low uptake of mammography among First Nations living on reserve are of particular concern. In the absence of recent, high-quality and comprehensive information on disease burden in First Nations in Ontario, this study provides important context for planning and priority setting.

In addition to lung cancer, smoking cigarettes is an established cause of many other types of cancer including mouth and throat, stomach, colorectal, pancreas, liver, cervix, ovary, kidney and bladder, and leukemia. ${ }^{27}$ Smoking also increases the risk of many other serious chronic conditions, including cardiovascular disease, chronic respiratory diseases and possibly diabetes. ${ }^{11,28}$ This study found a very high prevalence of smoking among First Nation adults and teens, especially those living on reserve, consistent with the high prevalence of smoking found among First Nations in other Canadian jurisdictions, ${ }^{29-31}$ suggesting a heavy future burden of tobacco-related cancers and chronic disease.

Alcohol is a major cause of serious health conditions including certain types of cancer. $^{32}$ If alcohol is consumed, cancer prevention guidelines recommend a limit of one drink a day for women and two drinks a day for men. ${ }^{9}$ Our study showed that First Nations living on reserve are more likely to abstain from alcohol. While this is promising, the prevalence of frequent binge drinking is also considerably higher among First Nations living on and off reserve compared to non-Aboriginal adults. Furthermore, First Nation adults, in particular men (both on and off reserve), are more likely to combine heavy drinking and smoking than are non-Aboriginal adults, substantially increasing their risk for cancers of the mouth and throat. ${ }^{32,33}$

Excess body weight increases the risk of many types of cancer, and risk for cancer rises with increasing BMI, even within the normal range. ${ }^{9}$ Maintaining healthy weights at either an individual or community level must involve consideration of a complex interrelationship of lifestyle factors including diet, physical activity and social determinants. ${ }^{34}$ The high prevalence of obesity combined with lower physical activity and limited vegetable and fruit intake observed in this study among First Nations (especially on reserve) are serious threats to good health and suggest a much higher risk for many chronic diseases, including cancer.

We observed a similar prevalence of Pap test uptake in First Nations (both on and off reserve) and non-Aboriginal women. These results are encouraging given that, historically, First Nation women were found to have significantly higher incidence of cervical cancer ${ }^{7}$ and poorer survival $^{8}$ compared to non-First Nation women in Ontario. Continued efforts to provide education and increase access to cervical screening as well as appropriate and timely follow-up of abnormal tests and human papillomavirus (HPV) vaccination are required to further reduce the burden of cervical cancer in First Nation women.

First Nation women living on reserve had lower uptake of mammography than their non-Aboriginal counterparts. Studies have also shown that First Nation women have poorer survival from breast cancer than non-First Nation women, possibly explained by later stage at diagnosis. ${ }^{8,35}$ Innovative solutions are required to improve access to breast cancer screening on reserve due to the complexity of mammography delivery, which requires sophisticated equipment and certified operators.

Colorectal cancer screening estimates are not available for First Nations living on reserve from the RHS. One study found that less than half of age-eligible First Nation adults living off reserve are up-todate with colorectal screening tests (42\%). ${ }^{12}$ Furthermore, studies suggest the incidence of colorectal cancer is increasing more rapidly among First Nation men and women, and survival from colorectal cancer is poorer compared to the nonFirst Nation population of Ontario. ${ }^{7,8}$

\section{Strengths and limitations}

This study presents a unique collaboration between two organizations, Cancer Care Ontario and the Chiefs of Ontario, with special access to restricted survey data that has enabled measurement and comparison of cancer risk for First Nations living on and off reserve compared to non-Aboriginal Ontarians adjusting for differences in age of the populations. Combining multiple years of data from the CCHS provided a large enough sample size for estimating risk in the off-reserve First Nation population. 
There are several limitations to address. Since both of these health surveys collect information through self-report, there may be a risk of social desirability bias, whereby survey respondents tend to underreport behaviours that are socially undesirable (e.g. smoking, drinking alcohol) and overreport behaviours that are considered desirable (e.g. alcohol avoidance, fruit and vegetable consumption, physical activity). It is unlikely that there would be a major difference in this effect across cultural groups, and therefore this would minimally affect the relative prevalence of any given risk factor.

Due to the nature of the questions and response categories in the RHS, some indicators deviated from the standard method of analysis and are therefore not directly comparable to other studies. These include vegetable and fruit consumption, which is typically measured as consuming vegetables and fruit five or more times per day (in any combination, and excluding potatoes) as per the cancer prevention guidelines; 9 excess alcohol intake, which is typically measured as intake exceeding cancer prevention guidelines (that is, no more than one drink a day for women or two drinks a day for men $^{9}$ ); breast cancer screening, which typically excludes women who had a mammogram for reasons other than screening and is measured according to the recommended breast screening interval of every two years for women at average risk; and cervical screening, which typically excludes women who have had a hysterectomy. Recommendations for more comparable questions have been made to RHS survey administrators, who will work to continue to improve the survey in future releases.

There was a lack of information on distal factors (e.g. issues in access to health services, social capital) available for this study. This limits our ability to explain some of the observed high-risk behaviours (such as frequency of binge drinking and poor intake of vegetables and fruit), and warrants further investigation. We did not adjust the estimates for differences in socioeconomic status between populations. In another recently published study of cancer risk factors and screening among First Nations living off reserve and Métis in Ontario, investigators found very little change in prevalence in the Aboriginal population compared with the nonAboriginal population after adjusting for income, education and rural/urban status. ${ }^{12}$ We performed chi-square tests as a statistical test for differences in proportions between First Nations and nonAboriginal Ontarians; however, these tests are influenced by large sample sizes. The point estimates and confidence intervals presented in this study primarily demonstrate the important differences between groups.

\section{Conclusion}

These results demonstrate that actions to improve the health of First Nations in Ontario (whether on or off reserve) are needed to reduce their future burden of cancer and other chronic diseases. There may be many social factors that determine whether an individual lives on or off reserve that should be considered when designing and implementing prevention policies and programs. The interaction between these factors, including distal (e.g. colonialism, social exclusion), intermediate (e.g. lack of community infrastructure, limited resources) and proximal (e.g. health behaviours, poverty, lower educational achievement, unemployment), ${ }^{36}$ and their influence on lifestyle choices among First Nations are complex and understudied. In one report, culturally appropriate, evidence-based health policy recommendations for avoiding tobacco and alcohol, eating a healthy diet and being physically active were documented for First Nations, Inuit and Métis populations in Ontario through knowledge and experience shared by communities, organizations and individuals in a series of focus groups and interviews. ${ }^{34}$ Further research of this kind is needed to inform the success of prevention initiatives. Implementation of policies and programs aimed at reducing the risk and burden of chronic disease in First Nations will require the support and participation of government and communities, and the collaboration of a wide range of organizations.

\section{Conflicts of interest}

The authors have no conflicts of interest to declare.

\section{Authors' contributions}

MM, AY, CJ, LM were involved in the design and/or conceptualization of the work. All authors were involved in acquisition, analysis or interpretation of the data and drafting and/or revising the paper. All authors have read and approved the final manuscript.

\section{References}

1. The Constitution Act, 1982, Schedule B to the Canada Act 1982 (UK), c 11. Part II: rights of the Aboriginal Peoples of Canada (Section 35); 1982.

2. Statistics Canada. Aboriginal peoples in Canada: First Nations people, Métis and Inuit [Internet]. Ottawa (ON): Statistics Canada; 2011 [modified 2016 Sep 15; cited 2016 Mar 3]. Available from: https://www12 .statcan.gc.ca/nhs-enm/2011/as-sa /99-011-x/99-011-x2011001-eng.cfm

3. Indigenous and Northern Affairs Canada. Registered Indian population by sex and residence 2014-Statistics and Measurement Directorate. Ottawa (ON): Government of Canada; 2015 [cited 2015 Sep 4]. Available from: http://www.aadnc-aandc.gc.ca/eng /1429798605785/1429798785836\#tbc 1303

4. National Collaborating Centre For Aboriginal Health. An overview of Aboriginal health in Canada: setting the context. Prince George (BC): NCCAH; 2013.

5. Tjepkema $M$, Wilkins $R$, Senécal $S$, Guimond E, Penney C. Mortality of Métis and registered Indian adults in Canada: an 11-year follow-up study. Health Rep. 2009;20(4):31-51.

6. Health Canada. First Nations and Inuit health: diseases and health conditions [Internet]. Ottawa (ON): Health Canada; 2016 Jan 15 [cited 2016 Jul 3]. Available from: http:// www.hc-sc.gc.ca/fniah-spnia /diseases-maladies/index-eng.php

7. Marrett LD, Chaudhry M. Cancer incidence and mortality in Ontario First Nations, 1968-1991 (Canada). Cancer Causes Control. 2003;14(3): 259-68.

8. Nishri ED, Sheppard AJ, Withrow DR, Marrett LD. Cancer survival among First Nations people of Ontario, Canada (1968-2007). Int J Cancer. 2015;136(3):639-45. 
9. World Cancer Research Fund/American Institute for Cancer Research (AICR). Food, nutrition, physical activity and the prevention of cancer: a global perspective. Washington (DC): AICR; 2007.

10. Parkin DM, Boyd L, Walker LC. 16 . The fraction of cancer attributable to lifestyle and environmental factors in the UK in 2010. Br J Cancer. 2011; 105(Suppl 2):S77-S81.

11. Cancer Care Ontario, Ontario Agency for Health Protection and Promotion (Public Health Ontario). Taking action to prevent chronic disease: recommendations for a healthier Ontario. Toronto (ON): Queen's Printer for Ontario; 2012.

12. Withrow DR, Amartey A, Marrett LD. Cancer risk factors and screening in the off-reserve First Nations, Métis and non-Aboriginal populations of Ontario. Chronic Dis Inj Can. 2014; 34(2-3):103-12.

13. Statistics Canada. Canadian Community Health Survey-Annual Component (CCHS): user guide [2007 microdata files]. Ottawa (ON): Statistics Canada; 2007.

14. Statistics Canada. Canadian Community Health Survey-Annual Component (CCHS): user guide [2008 microdata files]. Ottawa (ON): Statistics Canada; 2008.

15. Statistics Canada. Canadian Community Health Survey-Annual Component (CCHS): user guide [2009 microdata files]. Ottawa (ON): Statistics Canada; 2009.

16. Statistics Canada. Canadian Community Health Survey-Annual Component (CCHS): user guide [2010 microdata files]. Ottawa (ON): Statistics Canada; 2010.

17. Statistics Canada. Canadian Community Health Survey-Annual Component (CCHS): user guide [2011 microdata files]. Ottawa (ON): Statistics Canada; 2011.

18. Statistics Canada. Canadian Community Health Survey-Annual Component (CCHS): user guide [2012 microdata files]. Ottawa (ON): Statistics Canada; 2012.
19. Statistics Canada. Canadian Community Health Survey-Annual Component (CCHS): user guide [2013 microdata files]. Ottawa (ON): Statistics Canada; 2013.

20. Statistics Canada. Canadian Community Health Survey (CCHS) - Annual Component [Internet]. Ottawa (ON): Statistics Canada; 2015 [modified 2016 Jun 24; cited 2017 Feb 23]. Available from: http://www23.statcan.gc.ca /imdb/p2SV.pl?Function = getSurvey \&SDDS $=3226$

21. Thomas S, Wannell B. Combining cycles of the Canadian Community Health Survey. Health Rep. 2009; 20(1):53-8.

22. First Nations Information Governance Centre. About RHS [Internet]. Akwesasne (ON): First Nations Information Governance Centre; 2017 [cited 2017 Feb 23]. Available from: http://fnigc.ca/our-work/regional -health-survey/about-rhs.html

23. Chiefs of Ontario. First Nations Regional Health Survey (RHS) Phase 2 (2008/10) Ontario region final report: Ontario region report on the adult youth and children living in First Nations communities. Toronto (ON): Chiefs of Ontario; 2012. 135 p.

24. Association of Public Health Epidemiologists in Ontario (APHEO). 5A Smoking Status [Internet]. Toronto (ON): APHEO; 2015 [modified 2009 Jun 29; cited 2016 Jun 24]. Available from: http://core.apheo.ca/index.php ?pid $=117$

25. Chiefs of Ontario, Cancer Care Ontario. Cancer in First Nations in Ontario: risk factors and screening. Toronto $(\mathrm{ON})$ : Chiefs of Ontario and Cancer Care Ontario; 2016. 80 p.

26. Statistics Canada. 2006 Aboriginal population profile. 2006 census of population. Attawapiskat (ON): Statistics Canada; 2007 [Statistics Canada, Catalogue No.: 92-594-XWE].

27. Gandini S, Botteri E, Iodice S, et al. Tobacco smoking and cancer: a meta-analysis. Int $\mathrm{J}$ Cancer. 2008; 122(1):155-64.
28. US Department of Health and Human Services. The health consequences of smoking-50 years of progress: a report of the Surgeon General. Atlanta (GA): US Department of Health and Human Services, Centers for Disease Control and Prevention, National Center for Chronic Disease Prevention and Health Promotion, Office on Smoking and Health; 2014. 943 p.

29. Elias B, Kliewer EV, Hall M, et al. The burden of cancer risk in Canada's indigenous population: a comparative study of known risks in a Canadian region. Int J Gen Med. 2011;4:699-709.

30. Daniel M, Cargo MD, Lifshay J, Green LW. Cigarette smoking, mental health and social support: data from a northwestern First Nation. Can J Public Health. 2004;95(1):45-9.

31. Lemstra M, Rogers M, Thompson A, Moraros J, Tempier R. Prevalence and risk indicators of smoking among on-reserve First Nations youth. Paediatr Child Health. 2011;16(10):e71-e77.

32. International Agency for Research on Cancer. IARC monographs on the evaluation of carcinogenic risks to humans. Volume 100E. A review of human carcinogens. Part E: Personal habits and indoor combustions. Lyon (FR): International Agency for Research on Cancer; 2012. 598 p.

33. Hashibe M, Brennan P, Chuang SC, et al. Interaction between tobacco and alcohol use and the risk of head and neck cancer: pooled analysis in the International Head and Neck Cancer Epidemiology Consortium. Cancer Epidemiol Biomarkers Prev. 2009; 18(2):541-50

34. Cancer Care Ontario. Path to prevention-recommendations for reducing chronic disease in First Nations, Inuit and Métis. Toronto (ON): Queen's Printer for Ontario; 2016. 92 p.

35. Sheppard AJ, Chiarelli AM, Marrett LD, Nishri ED, Trudeau ME. Stage at diagnosis and comorbidity influence breast cancer survival in First Nations women in Ontario, Canada. Cancer Epidemiol Biomarkers Prev. 2011; 20(10):2160-7.

36. Reading CL, Wien F. Health inequalities and social determinants of Aboriginal peoples' health. Prince George (BC): National Collaborating Centre for Aboriginal Health; 2009. 36 p. 